\title{
A EDUCAÇÃO POPULAR EM PORTUGAL NO DEALBAR DO SÉCULO XX: O CASO DA VILA OPERÁRIA DO BARREIRO
}

\author{
Maria Manuela Pereira Figueiredo Rodrigues*
}

\section{RESUMO}

O presente texto procura traçar uma panorâmica das várias formas encontradas no início do século XX para difundir a cultura escrita e promover a formação elementar de adultos dentro de um contexto geográfico específico. A então vila do Barreiro (situada na margem sul do rio Tejo em frente da cidade de Lisboa) passou no espaço de escassas décadas, de uma simples terra de pescadores a um importante centro industrial, atraindo população de várias partes do país para as suas fábricas. E é esta população migrante, que precisa - ou sente surgir em si a necessidade - de ser alfabetizada e escolarizada, o nosso alvo de estudo: organiza-se em associações, cria cursos nocturnos e frequenta universidades populares.

PALAVRAS-CHAVE: Alfabetização. Escolarização. Ensino primário.

\begin{abstract}
The purpose of the present text is to outline a panoramic of the several forms found in the early XX century to spread the written culture and promote the basic formation of adults within a specific geographic context. At the time, Barreiro village (placed in the South boarders of the Tejo River in front of Lisbon) transformed, in few decades from a simple fisherman village to a main industrial center, drawing populations from several parts of the country in to its factories. It's precisely the migrate population who needs - or feels the need - to be alphabetized and schooled, being our study target: organized in associations, it creates night courses and attends popular universities.
\end{abstract}

* Doutora em Ciências da Educação na especialidade de Educação e Desenvolvimento, pela Universidade Nova de Lisboa, Professora do $1 .^{\circ}$ Ciclo do Ensino Básico e Membro do Centro de Investigação em Educação da Universidade de Lisboa. E-mail: mmpfrodrigues@hotmail.com 
KEY WORDS: Alfabetization. Escolarization. Elementary education.

\section{Em torno da escola...}

A ideia de uma instrução pública é uma ideia moderna que foi concebida e formulada na sua íntegra, pela primeira vez na Revolução Francesa. ${ }^{1} \mathrm{Se}$, na Antiguidade e no Feudalismo, a instrução estava como que vedada ao povo, agora, com as complicadas máquinas que a indústria criava, era preciso (en)formar indivíduos aptos a enfrentar as novas realidades. Assim, a escola foi a pedra basilar para a formação do trabalhador no seio das sociedades industrializadas na medida em que houve necessidade de homogeneizar as massas, com vista à implantação de mecanismos de ordem e integração num sistema diferente de racionalidade e de práticas sociais. A escola assume a sua função de agente de legitimação e de controlo social. Guy Vincent refere que "l'école du XIX ème ne forme pas l'ouvrier productif, mais le travailleur soumis et, plus géneralement, le citoyen". ${ }^{2}$ A escola de massas não foi criada propriamente para fornecer trabalhadores com as competências necessárias para a indústria, mas para ensinar obediência e submissão àqueles cujo destino se encontraria nos lugares mais baixos da hierarquia ocupacional, enquanto que a liderança, a determinação e o autocontrolo eram deixados para os que estariam destinados a ocupar os lugares mais graduados. A escola criou, então, uma série de ritos, regras, conceitos e expectativas, com vista a homogeneizar ritmos, valores e comportamentos de acordo com uma determinada visão do mundo. A socialização nesse espaço passa a ser feita de modo a permitir aos alunos a apreensão de um modus vivendi criador de identidades.

Sendo uma das facetas da instituição escolar a manutenção da estrutura social e a legitimação da mesma, não é, todavia, a única que devemos observar, pois ela tem igualmente, um papel no fluxo da mobilidade social. E é, essencialmente, nestas duas ópticas (tensões e

1 BUISSION, Ferdinand, Dictionnaire de Pédagogie et d'Instruction Primaire (extraits). Paris: Éditions Kimé, 2000 (1880-1887). p. 149.

2 VICENT, Guy. L'École Primaire Française. Etude Sociologique. Lyon: Presses Universitaires de Lyon, Editions de la Maison des Sciences de l'Homme, 1980. p. 102. 
conflitos versus consensos) que se tecem os discursos sobre a escola.

A nova sociedade nascida com a modernidade trouxe consigo uma mudança nas formas de vida e nas formas de pensar da população europeia. A partir do final do século XIX, cada vez mais as práticas discursivas sobre "crianças" vão sendo direccionadas para "alunos", no sentido de formação de cidadãos autónomos e responsáveis de um Estado-Nação. A passagem da educação escolar da esfera da Igreja para a esfera laica e secular traduziu-se num processo histórico cheio de vicissitudes. $\mathrm{O}$ emergir dos novos processos de produção industrial viria a cobrar à educação escolar toda uma série de novas funções e responsabilidades a que esta competia dar resposta. A escola enquanto organização tem uma dimensão propriamente educativa com finalidades culturais. Ao longo do seu percurso histórico e institucional, a escola adquiriu uma dimensão educativa que se foi sobrepondo a pouco e pouco à dimensão puramente instrutiva.

A institucionalização de um modelo de escola pública fez-se acompanhar pela organização do tempo escolar. A sociedade industrial emergente e o processo civilizador criaram novas configurações das noções de tempo e de espaço essenciais à construção dessa mesma sociedade, ávida de cidadãos preparados para o mercado de trabalho. A nova concepção de tempo e de espaço tinha como objectivo a maximização das energias e das forças do indivíduo com o fim de torná-lo o mais produtivo possível e, assim, promover a acumulação de riqueza. É dentro desse processo de mudanças que despontam a infância e a juventude como novas categorias sociais, e a quem se destinam as instituições escolares, agora responsáveis pela produção de indivíduos produtivos.

A ideologia burguesa reservou, para a infância, um tempo determinado institucionalmente que se ajustasse ao tempo do trabalho, nele se inserindo modos de vida e normas jurídicas. A escola toma o lugar do trabalho, embora tal se faça de acordo com as camadas sociais e as conjunturas locais. $\mathrm{O}$ tempo escolar não é mais do que uma fracção do tempo social total. A organização do tempo constituiu a matriz da revolução económica, o que conduziu ao aumento da produtividade, bem como ao alongamento e intensificação do trabalho. O tempo escolar é um princípio organizador da escolarização, definindo-se como um dispositivo específico de formação, instrução e inculcação; também se pode considerar 
como sendo um indicador privilegiado de atitudes e comportamentos com vista ao futuro.

A inspiração da ideia da organização da educação escolar por classes de idades pode-se reportar à sociedade medieval, em que a entrada da criança no mundo dos adultos ocorria por meio de processos de iniciação, tendo o aprendiz de percorrer certas etapas para obter crescentes graus de autonomia.

A extensão da escolarização a um universo cada vez mais alargado possibilitou a inserção de todos na sociedade de forma controlada. Segundo António Nóvoa, no que concerne ao século XIX, a história da escola tem de ser entendida no plano da ascensão da burguesia e da transformação do sistema sócio-económico, através de um duplo processo: "por um lado, a acção popular e burguesa em favor do desenvolvimento escolar; por outro lado, a penetração de um modelo cultural elitista na sociedade".

Em Portugal, a obrigatoriedade legal da escolaridade primária foi decretada em 1835 por Rodrigo da Fonseca Magalhães, mas só em meados do século XX se alcançaria estatisticamente a universalidade da escola primária no panorama nacional - a chamada escola de massas. A obrigação de ir à escola não deve ser confundida com o direito à instrução, na medida em que a obrigação aparece como a única forma de forçar a maioria da população a instruir os seus filhos.

O paradigma educativo da nossa sociedade depois da $2 .^{a}$ metade do século XIX é, indubitavelmente, a escolarização, tendo a medicina, a psicologia e a pedagogia contribuído para o triunfo da educação escolar. Progressivamente, a escola passa a ser universal, na medida em que começa a assistir-se à sua vulgarização junto do povo, obrigatória, porque tomam-se medidas legislativas impondo a frequência escolar das crianças, e gratuita, no sentido em que todas as despesas passam a ficar a cargo do Estado e das autoridades locais. Como dizia Ivan Illich, de forma algo sarcástica: "L'école est devenue la religion mondiale d'un prolétariat modernisé et elle offre ses vaines promesses de salut aux pauvres de l'ère

${ }^{3}$ NÓVOA, Antônio. Os professores: quem são? donde vêm? para onde vão?. In: Stephen Stoer (org.), Educação, Ciências Sociais e Realidade Portuguesa. Uma Abordagem Pluridisciplinar, Porto: Edições Afrontamento, 1991. p. 80. 
technologique" e acrescentava que "L'État-nation a adopté cette religion, enrôlant tous les citoyens et les forçant à participer à ses programmes gradués d'enseignement sanctionnés par des diplômes". ${ }^{4}$

A escola, enquato instituição, teve um papel crucial na formação de cidadãos, na unificação cultural e linguística desses, e foi um instrumento imprescindível na construção dos modernos Estados-Nação, de tal modo que o ensino e a aprendizagem estiveram sempre envoltos por relações de poder, pelo qual nunca podemos atribuir neutralidade nos seus efeitos e resultados.

\section{2 - Aspectos da alfabetização das classes populares}

O problema do analfabetismo foi uma constante ao longo dos tempos. No final do século XVIII, possuir conhecimentos escolares ainda não constituía uma necessidade para a maior parte da população, particularmentenas regiões rurais onde as pessoas continuavam mergulhadas na cultura oral e os limites dos seus horizontes não ultrapassavam os da aldeia onde viviam. A transmissão por imitação do saber prático e técnico necessário à vida quotidiana sobrepunha-se à ideia de ser necessário ler e escrever. Contudo, à medida que se vão constituindo "communautés de lecteurs" (expressão utilizada por Anne Marie-Chartier), a cultura oral vê-se relegada para um plano subalterno: "la culture oral, mêlant la mémoire vive et l'échange direct, la prise de parole et les gestes pratiques, la répétition, la déformation et l'oubli, deviendrait peu à peu résiduelle et folklorique". ${ }^{5}$ Aos poucos a escola adquire uma função determinante e diferencia-se de outras instâncias de socialização pelo papel social que lhe é atribuído na transmissão de conhecimentos: "Com efeito, quando as massas passam a ter acesso à instrução primária, a cultura tradicional deixa de ser basicamente oral e fragmenta-se numa cultura superior ou

${ }^{4}$ ILLICH, Ivan D. Une Société Sans École. Paris: Éditions du Seuil, 1971. p. 27. Illich dizia ainda que "Le système de la scolarité obligatoire, s'il conduit inévitablement à une ségrégation au sein de la société, permet également une sorte de classement entre les nations" (p. 25).

${ }^{5}$ CHARTIER, A. M. Le lecture scolaire entre histoire des disciplines et histoire culturelle. In Éducation et sociétés. Revue internationale de Sociologie de L'Éducation, n. 4. Issy-les-Moulineaux/France: De Boeck Université, 1999/2. p. 124. 
dominante, a dos alfabetizados, e numa cultura inferior ou recessiva, a dos analfabetos". ${ }^{6}$ Todavia, a alfabetização não se reduziu ao produto da oferta de escolas e da atracção que estas exerceram, mas, antes disso, ela foi o resultado da opção dos indivíduos em determinadas circunstâncias, como acontecia com certos grupos sócio-profissionais (por exemplo, clérigos e comerciantes) cuja alfabetização se ficou a dever ao papel que a escrita assumia nas suas actividades.

Na segunda metade do século XIX, na Europa Central e Ocidental (de modo particular nas regiões protestantes) bem como na América do Norte, a distinção entre alfabetizados e analfabetos era já uma poderosa força de modificação do mundo rural, como salienta Hobsbawn: enquanto que no mundo oral dos iletrados, a ausência de conhecimento das letras, da língua nacional ou das instituições nacionais apenas constitui uma desvantagem para aqueles cuja profissão exige esse conhecimento, já numa sociedade alfabetizada o iletrado é por definição inferior e, por isso, sente-se fortemente estimulado a suprimir essa inferioridade, senão em si, pelo menos nos seus filhos. ${ }^{7}$ Contudo, Guy Vincent chama a atenção para o facto de não se poder associar a escolarização da criança, especialmente a dos meios mais desfavorecidos, com a formação de trabalhadores:

Le nouveau rapport à l'enfant qui s'instaure à une époque dans nos sociétés est très certainement lié aux autres rapports sociaux, et à leur transformation, mais la scolarisation de l'enfance ne peut être identifiée à une opération bourgeoise de transformation des enfants pauvres en travailleurs utiles. La clôtion, la séparation de l'école par rapport au monde et à la vie, n'apparaissent pas comme la conséquence de la division capitaliste du travail, d'une séparation entre travail intellectuel et travail manuel liée à la contradiction capital-travail, mais comme un moyen d'assurer une emprise que ne permettent pas les interventions tardives et intermittentes dans le milieu. ${ }^{8}$

\footnotetext{
${ }^{6}$ HOBSBAWN, E.J. A Era do Capital 1848-1875, Lisboa: Editorial Presença, 1979. p. 401.

${ }^{7}$ Ibidem, p. 254.

${ }^{8}$ VINCENT, Guy. ob. cit., 1980. p. 54.
} 
Desde 1852 que o direito à educação e à instrução constava nos programas reivindicativos globais da classe operária portuguesa. O socialista português da geração de 1852, Custódio José Vieira, reclamava a criação de escolas infantis ou creches para os filhos das classes trabalhadoras, um ensino primário com a duração de quatro anos seguido de uma educação, simultaneamente, literária e profissional incidindo nas artes e ofícios e no ramo agrícola. Porém, o direito à igualdade de oportunidades, em educação, não era reconhecido por todos, sendo exemplo disso a posição de Almeida Garrett, que entendia que as bases da educação geral seriam idênticas para todos os seres humanos, mas "a situação de classe, o sexo, as expectativas sociais modificála-iam: "A educação é uma só: o sexo, a posição social, os destinos futuros do educando a modificam de mil modos, mas a sua natureza permanece a mesma.". 9 Por seu turno, Alexandre Herculano, já em 1838, considerava prioritária a educação do povo - "Nós carecemos mais de ilustrar o povo do que de fazermos sábios." 10 - e condenava o facto de a classe trabalhadora ter sido tradicionalmente excluída dos benefícios da cultura.

Se, na perspectiva marxista, a fábrica é entendida como um lugar de sofrimento e de cansaço extenuantes, ao mesmo tempo e de forma oposta, esse mesmo lugar de desqualificação é também o lugar em que se dá a qualificação, uma vez que o saber fabril apetrecha o operário para a luta, dá-lhe, através da experiência sindical, um aumento da sua autoconfiança e consciência de classe para a transformação da divisão do trabalho e, por consequência, para a mudança da sociedade. A fábrica e o sindicato eram importantes para a instrução dos trabalhadores. Na Europa, as actividades de formação sindical e/ou operária tiveram início a partir dos finais do século XVIII, com a preocupação prática de dar instrução aos trabalhadores adultos, ou seja, com objectivos técnico-profissionais, havendo para o efeito cursos nocturnos. No final do século seguinte, esse movimento de educação toma duas vertentes: por um lado, há a corrente que mantém o objectivo de educar o povo e que resulta no nascimento das universidades populares já no século XX; a outra corrente desenvolveu-se

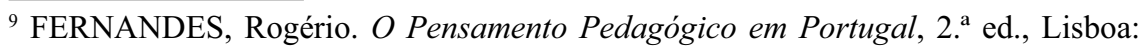
Instituto da Cultura e Língua Portuguesa, Ministério da Educação, 1992. p. 97.

${ }^{10}$ Citado em FERNANDES, Rogério. ob. cit., 1992. p. 103. 
separadamente e centrou as suas actividades nas necessidades de formação dos adultos e da promoção profissional. No que concerne ao problema da instrução dos trabalhadores, Émile Durkheim dizia que:

On a parfois proposé comme remède de donner aux travailleurs, à côté de leurs connaissances techniques et spéciales, une instruction générale. Mais, à supposer qu'on puisse ainsi racheter quelques-uns des mauvais effets attribués à la division du travail, ce n'est pas un moyen de les prévenir. La division du travail ne change pas de nature parce qu'on la fait préceder d'une culture générale. Sans doute, il est bon que le travailleur soit en état de s'intéresser aux choses de l'art, de la littérature, etc.; mais il n'en reste pas moins mauvais qu'il ait été tout le jour traité comme une machine. ${ }^{11}$

Ao longo do século XIX a interpenetração da ciência e da indústria levou a que o sistema educacional se tornasse, a pouco e pouco, num factor imprescindível para o desenvolvimento industrial. Países como a Inglaterra e a Bélgica, que foram pioneiros da primeira fase da revolução industrial, não estavam na lista dos países mais industrializados. Contudo, como refere Hobsbawm, doravante, tornou-se praticamente impossível que um país, que não fosse dotado de um sistema de educação de massas e de instituições universitárias adequadas, se tornasse uma economia "moderna"; por outro lado, alude ao facto de países pobres e retrógrados como a Suécia, mas dotados de um bom sistema educacional, terem tido mais facilidade em atingir o estádio industrializado. ${ }^{12}$ Contudo, a escolarização não era uma condição imprescindível para se singrar na vida: "Industry, skills, and wealth could be obtained by the individual with no schooling; education, nevertheless, was viewed as fundamental to the development and the maintenance of the economic system, as it was to the social order". ${ }^{13}$

${ }^{11}$ DURKHEIM, Émile. De la Division du Travai Social, 2.è édition, Paris: Presses Universitaires de France, 1986 (1893). p. 364.

${ }^{12}$ HOBSBAWN, E. J. ob. cit., 1979. p. 64-65. De acordo com Hobsbawn, o valor prático de uma boa educação primária via-se até no campo de batalha, pois um dos motivos que contribuíram para que os prussianos batessem os franceses em 1870-71 foi o grau muito superior de alfabetização dos seus soldados .

${ }^{13}$ GRAFF, H. J., The Literacy Myth: cultural integration and social structure in the 
Em Portugal, mesmo em plena 1. ${ }^{a}$ República, a deficiente formação dos recursos humanos ocupados na indústria continuava a ser notada e a constituir um dos obstáculos colocados à industrialização do país: "mais do que a escassez de recursos naturais, foi a falta de recursos humanos (operários, técnicos e dirigentes), devidamente preparados e actualizados, que, no período em foco (1890-1926), travou o ritmo da industrialização em Portugal". ${ }^{14}$ Para retratar a imagem que se tinha na época sobre a importância atribuída à educação escolar na formação da classe operária, escolheu-se um excerto do livro História da Indústria Portuguesa:

O Eng. ${ }^{\circ}$ José de Oliveira Simões, geralmente bem informado sobre as questões industriais, retratara assim a situação: "Em poucas palavras pode dizer-se que não se dá a educação devida à classe operária, e nem mesmo o ensino indispensável se lhe ministra." Mas a lacuna não se restringia aos operários: "A falta de instrução geral e especial explica a deficiência que se nota nas nossas oficinas, quanto a pessoal dirigente. Embora a tendência seja para diminuir o défice nacional, o pessoal de mestres e contramestres é em grande parte estrangeiro." ${ }^{15}$

A questão da falta de mão-de-obra especializada em Portugal, que levava à sua importação do estrangeiro, pode ter explicação não só no atraso industrial do país, mas noutros factores bem distantes. Se tivermos em linha de conta que Portugal sempre foi um país profundamente católico, talvez possamos encontrar parte da explicação, reportando-nos ao trabalho de Max Weber:

Ainda mais significativa é uma constatação que ajuda a compreender a baixa percentagem de católicos na mão-de-obra qualificada da grande indústria moderna. [...] Por outras palavras, os artesãos

nineteenth century, New Brunswick, New Jersey: Transaction Publishers, 1991, (originally published in 1979). p. 200.

${ }^{14}$ RODRIGUES, Manuel F.; MENDES, José A. História da Indústria Portuguesa. Da Idade Média aos Nossos Dias, Mem-Martins: Associação Industrial Portuguesa, Publicações Europa-América, 1999. p. 275.

${ }^{15}$ Ibidem. p. 274. 
católicos mostram uma tendência mais acentuada para permanecerem na oficina, tornando-se assim com maior frequência mestres artesãos, ao passo que os protestantes se encaminham mais para a fábrica, para aqui ocuparem os escalões superiores da mão-de-obra qualificada e empregos administrativos. Nestes casos, a relação de causalidade reside indubitavelmente no facto de as peculiaridades espirituais inculcadas, nomeadamente pela educação baseada na atmosfera religiosa da comunidade de origem e da casa paterna, terem determinado a escolha da profissão e a subsequente carreira profissional. ${ }^{16}$

Apesar de todo esse atraso educativo, os militantes operários bem como os próprios governos atribuíam grande importância à educação dos trabalhadores. Assim, dirigentes, activistas sindicais, trabalhadores mais qualificados e artesãos, geralmente pelos seus próprios meios, tentavam ampliar os seus conhecimentos e transmiti-los aos demais. Eles procuravam suprir as deficiências do sistema escolar da época, empenhando-se em obter uma sólida preparação teórica, a fim de contraporem o seu saber ao conhecimento burguês ou religioso. Por outro lado, essa preocupação educacional tinha também finalidades políticas, como a criação de grémios de debate que serviam de foco de aglutinação e politização dos trabalhadores, porque a educação popular não devia ficarse pela formação de sobrevivência técnica: um bom operário não era o que sabia fazer funcionar as máquinas, mas sim aquele que ao funcionar com elas reconhecia a razão de ser histórica e social da própria máquina e reconhecia a favor de quem trabalhava a máquina com as suas mãos. A partir da sua experiência e com o recurso à instrução que conseguiam obter, os trabalhadores constituíam um quadro essencialmente político da organização da sociedade. Com esta posição face à instrução, conseguia-se deitar por terra o que Illich via de profundamente negativo na ideologia escolar, quando afirmava que, "Prisonnier de l'idéologie scolaire, l'être humain renonce à la responsabilité de sa propre croissance et, par cette abdication, l'école le conduit à une sorte de suicide intellectuel". ${ }^{17}$

${ }_{16}$ WEBER, Max. A Ética Protestante e o Espírito do Capitalismo. Lisboa: Editorial Presença, 1983 (tradução - original em alemão escrito entre 1904 e 1905). p. 27.

${ }^{17}$ ILLICH, Ivan. ob. cit., 1971. p. 106. 
Todavia, a questão do autodidactismo trazia alguns problemas: no seu esforço de promoção cultural o autodidacta perde os seus laços de classe, a tal ponto que, por vezes, chega a ter vergonha das suas origens proletárias, sentindo-se superior e com tendência a "olhar do alto" as atitudes e maneiras populares..$^{18}$ Por isso, havia quem visse o alargamento da alfabetização aos meios populares como um mal a evitar a todo o custo. Se, de um lado, havia quem defendesse a necessidade de instruir as massas de modo a elevá-las ao nível das técnicas da nova produção, do outro lado, havia o temor que essa mesma instrução as tornasse "menos assustadiças e menos humildes". ${ }^{19}$ Nesse sentido, Jürgen Kuczynski chama a atenção para o facto de, durante o século XIX, haver nas classes dirigentes quem visse a educação popular como um fenómeno perigoso, a tal ponto que uma parte opunha-se completamente a qualquer progresso nesse domínio. ${ }^{20}$ Mas, em contrapartida, também havia na burguesia quem "subjectivement animé de sentiments humains et favorables aux ouvriers, voulait donner de l'instruction à ceux-ci pour les transformer en une petite bourgeoisie, bien à sa place dans la société ou, en termes politiques, pour en faire des élécteurs pour les conservateurs ou les libéraux [...]."21

Como era o nível de alfabetização do meio em que se vivia, e não tanto o modo de vida ou a condição social, o factor que mais determinava a própria alfabetização, em Portugal, durante a centúria de Oitocentos, "o analfabetismo era suficientemente elevado para se perpetuar a si próprio". ${ }^{22}$ $\mathrm{Na}$ tentativa de erradicar esse mal que assolava a sociedade portuguesa, criaram-se escolas móveis, sendo esse um dos argumentos, segundo António Candeias, que justifica o interesse das instituições republicanas

\footnotetext{
${ }^{18}$ HOGGART, Richard. As Utilizações da Cultura 2. Aspectos da vida cultural da classe trabalhadora. Lisboa: Editorial Presença, 1975 (1957). p. 171.

${ }^{19}$ PONCE, Anibal. ob. cit., 1979 (1936). p. 200.

${ }^{20}$ KUCZYNSKI, Jürgen. Les Origines de la Classe Ouvriére, Paris: Hachette, 1967. p. 109.

${ }^{21}$ Ibidem. p. 130.

${ }^{22}$ RAMOS, Rui. O chamado problema do analfabetismo: as políticas de escolarização e a persistência do analfabetismo em Portugal (séculos XIX e XX), In: Ler História, 35, 1998. p. 48.
} 
pela causa da instrução popular. ${ }^{23}$ Em 1920, os dados apontam para uma percentagem de população alfabeta de idade igual ou superior a dez anos de $35 \%$ e, em 1930, esse valor sobe para os $40 \% .{ }^{24}$ Aliás, a Inglaterra do século XVIII era uma sociedade com uma taxa de alfabetização muito elevada comparativamente a Portugal em $1930 .{ }^{25}$ O próprio João de Barros admitia que "Todos somos culpados dum grande erro, em Portugal, dum grande erro que vem de longe - e que não soubemos combater: - é o erro de ter desprezado a educação e o ensino português". ${ }^{26}$ A carência de uma linha directriz é a grande falha apontada e, neste ponto, conseguimos salientar em João de Barros uma visão embrionária da teoria do capital humano que iria despoletar umas décadas mais tarde:

O que é preciso é saber determinar os limites da acção pedagógica dentro dos quais se conseguirá fazer do educando um homem útil à sua Pátria e a si próprio. O que é preciso é estabelecer as bases gerais em que a sua inteligência e a sua sensibilidade se apoiem para alcançarem o máximo de força produtiva, no campo em que se apliquem as actividades individuais. E é preciso ainda [...] que o Estado possua um bom critério orçamental em matéria de ensino, não para poupar ridiculamente na organização deste serviço público, mas para que, por meio deste, obtenha o capital de energia humana sem o qual os outros capitais são quase inexistentes e improdutivos. ${ }^{27}$

\footnotetext{
${ }^{23}$ CANDEIAS, António (dir. e coord.). Alfabetização e Escola em Portugal nos Séculos XIX e XX. Os Censos e as Estatísticas, Lisboa: Fundação Calouste Gulbenkian, 2004. p. 127. A Associação das Escolas Móveis (fundada em 1882 por Casimiro Freire) não seria a única associação criada durante a Monarquia com o intuito de combater o analfabetismo. Em 1907, surgiu a Liga Nacional de Instrução com a preocupação de secularizar a sociedade portuguesa republicana. Os seus objectivos centravam-se no combate ao analfabetismo, na criação de uma verdadeira educação cívica e social e na renovação da Pátria através da instrução e da educação.

${ }^{24}$ Ibidem. p. 137 e 147.

${ }^{25}$ MÓNICA, Maria Filomena. A Sociedade, o Estado e a Educação Popular: Inglaterra, Portugal e Japão. In: Análise Social. vol. XII (48), 1976-4. p. 863.

26 BARROS, João de. O Problema Educativo Português. Ensaio crítico. Lisboa: Imprensa Libanio da Silva, 1920. p. 18.

${ }^{27}$ Ibidem. p. 17.
} 


\section{Caracterização sumária da vila operária do Barreiro}

Não se pode falar do Barreiro do final do século XIX inícios do XX sem aludir ao seu excepcional posicionamento geográfico frente a Lisboa e ao facto de ser uma estação terminal das ligações ferroviárias que se alargavam ao sul do país. A presença do terminal dos Caminhosde-Ferro do Sul e Sueste "chamou para esta Villa, as importantes fábricas de preparação de cortiça e rolha que até então estavam dessiminadas por algumas terras do Alentejo" e, como o movimento comercial se tornara importante, "o Governo julgou necessario estabellecer nesta Villa a séde de uma secção fiscal com 25 praças commandadas por um alferes". ${ }^{28} \mathrm{O}$ início do processo de industrialização do Barreiro deu-se, então, com a implantação das linhas ferroviárias e com o surgimento das primeiras fábricas de cortiça, nos inícios do último quartel do século XIX. A instalação e o subsequente desenvolvimento do caminho-de-ferro fizeram do Barreiro um ponto de passagem obrigatório de diversos tipos de mercadorias e bens, que transitavam entre a capital e a parte sul do país; por consequência, isso levou à fixação das oficinas ferroviárias na vila e, também, obrigou à criação de uma frota de embarcações de apoio ao tráfego fluvial que, naturalmente, se estabeleceu (fragatas, varinos, faluas, canoas, muletas, ...). Com a implantação das linhas ferroviárias, que tinham no Barreiro a estação terminal, começaram a instalar-se, também, fábricas de cortiça, cuja produção era facilmente escoada através dessa nova via de comunicação. Assim, a pacata vila de moleiros e pescadores dava lugar à enérgica vila de ferroviários e corticeiros.

Contudo, a grande transformação do Barreiro dar-se-ia mais tarde, a partir de 1907, com a instalação de importantes fábricas da Companhia União Fabril (CUF), que dariam a essa terra a imagem fortemente industrial que ainda se lhe associa. O início da construção das instalações da CUF no Barreiro ocorreu em 1907, com a edificação da primeira fábrica destinada a extracção do azeite e dos bagaços; a partir de 1908 são instaladas as primeiras fábricas de ácidos e adubos, de laminagem de chumbo, de sulfato de cobre e de ferro, de soda, de magnésio, de ácido clorídrico, de

${ }^{28}$ Livro de actas das sessões da Câmara Municipal do Barreiro. 1895-1897, 30 Mar 1895. 
refinação de copra. Em 1916, o complexo do Barreiro abrangia 20 hectares de superfície, onde trabalhavam 2.000 operários. ${ }^{29}$ Dessa forma, o Barreiro acabaria por se constituir como um pólo demográfico da região sul do país, bem como de uma parte das Beiras. A implantação da CUF no Barreiro fez desse uma "ilha" de modernidade industrial num país marcadamente caracterizado pela ruralidade e pela primazia do sector primário na estrutura económica nacional.

O retrato do Barreiro nos princípios da década de vinte é-nos dado de forma bastante clara num artigo intitulado "Costumes", publicado na primeira página de um quinzenário local e redigido pelo seu director:

Escrevendo sobre costumes é minha intenção relatar sobre o que penso do Barreiro onde hoje vivo e trabalho. Nesta terra vive-se mal, impera a miséria, falta a higiene, maus costumes, vícios, sofre-se muito, lutase com a falta de meios mais necessários à vida; como por exemplo: o problema da habitação apresenta-se duma forma verdadeiramente assustadora; em casas pequenas sem higiene, sem luz, mal construídas, vivem dezenas de creaturas; casos há, que, num pequeno quarto dormirem dezenas de creaturas conservando neste ambiente os seus dejectos; juntando-se a falta de alimentação e da assistência, enfim; a miséria com o seu quadro negro de esfarrapados e doentes. ${ }^{30}$

Mas também haviam aspectos positivos que o articulista fazia sobressair: "Aqui trabalha-se muito; há espírito de iniciativa; o meio associativo no Barreiro está muito desenvolvido, todas as classes estão associadas". ${ }^{31}$ E continuava o seu artigo mencionando a existência de algumas associações de socorros mútuos, associações de beneficência, sociedades filarmónicas, clubes dramáticos e desportivos, centros escolares,

${ }^{29}$ RODRIGUES, Manuel Ferreira; MENDES, José M. Amado. ob.cit., 1999. p. 258. O complexo fabril CUF possuía uma ampla doca, $16 \mathrm{~km}$ de linha férrea que iam entroncar nas linhas do Barreiro e da Moita, para além de instalações recreativas, comerciais e de apoio social para os seus trabalhadores.

${ }^{30}$ Acção, Quinzenário de educação e propaganda dos interesses do Barreiro, ano I, n. 6, Barreiro, 10 Jan 1921.

${ }^{31}$ Ibidem. 
lojas maçónicas e algumas cooperativas; referia, ainda, o desenvolvimento da indústria e do comércio. Como remédio para os males do Barreiro dizia ser necessário a uniformização dos costumes "duma forma moral e respeitosa, pois que o motivo desta depravação está na heterogeneidade da população que se compõe de creaturas de várias terras". 32

Com efeito, esta multiplicidade de gentes veio trazer novos problemas sociais:

Em larga medida, a industrialização veio absorver os imigrados rurais que até aí constituíam a principal fonte do pauperismo, mas, simultaneamente, ela traz a este uma nova natureza e uma outra extensão. Doravante fundidas, as massas da população operária, proletários urbanos e rurais, vão criar a imensa área social da miséria. O estatuto do operário é assimilado ao do pobre: condições de vida e de alojamento, estado de saúde, famílias numerosas, aspecto exterior, comportamentos sociais são os traços distintivos da indigência através dos quais se reconhece como idênticos operários e miseráveis. ${ }^{33}$

A evolução sócioeconômica ao longo dos séculos XIX e XX tende a uma progressiva melhoria das condições de vida da população operária, pelo que a associação pobre/operário se inclinará para deixar de fazer sentido; por outro lado, a conjuntura social passou por crises mais ou menos generalizadas que conduziram à deterioração temporária das condições de vida dos trabalhadores. Enfim, podemos dizer que o povo do Barreiro esteve sempre envolto pela conquista de trabalho e do que ele consubstanciava: "O pão, objectivo polivalente de que dependem a vida, a morte, o sonho, torna-se na sociedade pobre, um objectivo cultural, o centro e o instrumento culminante, real e simbólico da própria existência $[\ldots]$ ". ${ }^{34}$

\footnotetext{
${ }^{32}$ Ibidem. Segundo dados publicados no mesmo quinzenário, em 5 de Março desse ano, a população tinha sofrido os seguintes aumentos: em 1864 era de apenas 4.545 habitantes, em 1878 tinha já 4.843, em 1890 aumentava para 5.436, em 1917 ascendia aos 12.262 e estaria no início de 1921 nos 16 a 17 mil habitantes (Acção, ano I, n. 9, 5 Mar 1921).

${ }^{33}$ GEREMEK, Bronislaw. A Piedade e a Forca. História da miséria e da caridade na Europa. Lisboa: Terramar, 1995 (1986). p. 270.

${ }^{34}$ COMPORESI, Piero. O Pão Selvagem, Lisboa: Editorial Estampa, 1990. p. 11.
} 


\section{A alfabetização dos barreirenses: problemas e soluções}

Apesar da carência de escolas que se fazia sentir, há uma preponderância da alfabetização da população barreirense relativamente à média da alfabetização da população dos restantes concelhos do distrito de Setúbal. A explicação para um índice de analfabetismo mais baixo na população do Barreiro, pode ser encontrada na essência do seguinte excerto, de uma notícia publicada em Janeiro de 1922, que divide a população da terra em duas classes:

A primeira, produto da heterogénea composição familiar em que assenta o censo desta vila, vive rudemente, autómata, como um ser que não pensa nem sabe o que pensar. A segunda, composta d'uma actividade cerebral grande, chegou já à mais sublime existência, ao mais belo prazer que é o viver idealista. [...] A demonstração clara, evidente, como é composta, como e onde existe a segunda parte desta família que é o Barreiro, está na forma como essa classe recebe o mundo idealista, o mundo que vive, que se movimenta, que aciona. Da partitura ao palco, da oficina ao pincel, essa parte - a maior felizmente - existe com noções exatas do que é a arte, desde o mais pequeno significado da palavra à mais maravilhosa demonstração. É que essa classe mesmo sem mestres, que a leccione, tem conseguido acompanhar o movimento sempre contínuo e interminável do ideal. É a maior prova da sua mentalidade. Sem mestres nem escolas a segunda parte em que dividimos a população do Barreiro, sabe interpretar Mozart e Talma, sabe compreender e definir. E como se não fosse isso o suficiente - como não é - distingue as teorias revolucionárias de Karl Marx às reformistas do educador que foi Malon. ${ }^{35}$

Os meios de promoção da alfabetização na classe operária passavam também pela difusão do esperanto, como o atesta a notícia de Outubro de 1922, publicada na primeira página do semanário O Sul e Sueste, na qual se comunica que o Grupo Ferroviário Educação Social, numa das suas últimas reuniões, havia decidido fundar na sua sede uma escola de esperanto, para

${ }^{35}$ Acção, ano II, n. 27, Barreiro, 30 Jan 1922. 
o que já haviam tomado as diligências necessárias. ${ }^{36}$

Há a considerar a hipótese da mobilidade social ser possível e provável no mundo industrial do Barreiro, o que levaria os trabalhadores a serem autodidactas (por exemplo, começariam em aprendiz e podiam ascender a postos de chefia dentro de determinados sectores ou na liderança associativa sindical), enquanto tal é praticamente improvável no meio rural, sendo assim esse um factor de desenvolvimento cultural. A fábrica ocuparia o lugar privilegiado da escola como local de aprendizagem de saberes letrados, quer como indutora de vontade de aprendizagem quer como local de discussão e troca desses saberes. A partir dos dados recolhidos, podemos apontar para a existência de uma ligação directa entre política e alfabetização nesse contexto geográfico e temporal.

Em 1890 foi fundado o $1 .{ }^{\circ}$ Centro Socialista no Barreiro, também local de residência do seu fundador, Joaquim Marques, maquinista dos vapores do Sul e Sueste; o $2{ }^{\circ}$ Centro Socialista seria fundado em 1897 por quatro operários corticeiros e um comerciante local; ambos os Centros tiveram uma existência efémera. Só em 1909 nasceria um $3 .^{\circ}$ Centro Socialista no Barreiro - na prática correspondia ao renascimento do anterior Centro -, a que estaria ligada a fundação de um jornal, o Avante; para além do jornal, seria inaugurada na sede do Centro uma biblioteca, denominada posteriormente Livraria Pública que autorizava o empréstimo domiciliário, e um curso de desenho industrial e de francês. ${ }^{37}$ Também esse Centro teria uma curta existência, pois, com a implantação da República, houve uma forte adesão ao P.R.P., tendo a maior parte dos socialistas barreirenses sido absorvidos pelo Centro Republicano Estêvão de Vasconcelos, pelo que não se justificava a continuação desse projecto. $\mathrm{O}$ 4. ${ }^{\circ}$ Centro Socialista foi apelidado de Centro Socialista Burguês, devido ao

${ }^{36}$ O Sul e Sueste, Semanário do sindicato do pessoal dos Caminhos de Ferro do Sul e Sueste, ano IV, n. 66, Barreiro, 15 Out 1922.

${ }^{37}$ Os trabalhos para a fundação deste Centro, que ficava sob a alçada da Comissão Central do Partido Socialista instalada em Lisboa, tiveram início em Maio de 1909, numa sessão realizada na antiga Associação da Classe dos Operários da Indústria Corticeira. Uma das pessoas ligadas à origem deste $3 .^{\circ}$ Centro era uma mulher, Ernestina Costa, que fundou, também no Barreiro, a União Fraternal das Mulheres, cuja primeira missão era enveredar esforços para a criação de uma creche para os filhos dos operários. 
facto de alguns dos seus sócios serem pequenos industriais corticeiros ou comerciantes, o que conduziu ao afastamento de muitos operários que se viraram para os sindicalistas, particularmente os dos Caminhos-de-Ferro; teve igualmente curta existência, o que ficou a dever-se, em grande medida, ao estrangulamento que os republicanos fizeram dos pequenos centros socialistas locais. Na mesma rua do $1 .^{\circ}$ e do $4 .^{\circ}$ Centros, seria fundado o último dos Centro Socialistas do Barreiro, o 5. ${ }^{\circ}$ Centro Socialista, em 1920, mas que encerraria portas em 1922; editou também, entre 1920 e 1924, um jornal - Acção - com o fim de defender os interesses locais e com uma vertente cultural, tendo conseguido sobreviver dois anos ao Centro sob cuja égide havia sido fundado.

A Associação de Classe dos Ferroviários do Sul e Sueste criou, em 1919, o seu próprio órgão de imprensa, o jornal Sul e Sueste, nascido a partir da unidade dos antigos ferroviários desavindos (o primeiro jornal ferroviário barreirense, O Rail, apareceu em 1915, mas teve vida efémera), e que perduraria até 31 de Dezembro de 1933, altura em que seria obrigado a encerrar devido à aplicação da lei que criava os Sindicatos Nacionais. Tratava-se de um jornal "das grandes lutas da classe contra a administração e contra o sindicato paralelo". ${ }^{38}$ Atendendo ao fato de nesses tempos republicanos, um periódico ser o veículo porta-voz, por excelência, de uma dada classe, destinado a atingir uma população operária escolarizada,

Escrever num jornal ou falar nas grandes assembleias de massas, participar na vida do sindicato ou das múltiplas associações que enxameiam o Barreiro desta época, é uma forma de prestígio para um escol de dirigentes que despontou e dominava, efectivamente, o operariado de uma das mais desenvolvidas regiões industriais do país. ${ }^{39}$

${ }^{38}$ MOREIRA, António. A poesia num jornal operário - O Sul e Sueste, 1919-1933. In: Um Olhar Sobre o Barreiro, II série, n. 3, Jun 1990. p. 30. O jornal Eco do Barreiro, também ligado aos ferroviários, pertencia ao partido Evolucionista; o fundador deste jornal, Jerónimo Paiva, havia sido director do jornal O Rail, e também em 1919, o Grémio Ferroviário do Sul e Sueste editou o jornal Eco Ferroviário tendo-o a ele como director, editor e proprietário.

${ }^{39}$ Ibidem, p. 34. 
A República permitiu e promoveu uma participação cada vez mais politizada das classes populares, permitiu uma maior mobilidade à actividade política e incentivou a prática do associativismo político. $\mathrm{O}$ aparecimento dos partidos e das primeiras organizações operárias traduziuse num desenvolvimento acentuado nas instâncias promotoras do ensino. A atenção dada pelos militantes sindicalistas às questões de solidariedade e de educação deve ser vista na perspectiva em que é entendido o próprio sindicato, uma vez que esse é tido não só como um organismo de resistência, mas também como uma instituição moral, "cujo aperfeiçoamento deverá traduzir-se, nas condutas dos seus membros, por atitudes mais emancipadas, livres e solidárias" ${ }^{40} \mathrm{O}$ interesse dos sindicalistas pelo tema da educação materializou-se, sobretudo, pela criação de escolas por parte dos sindicatos. No caso do Barreiro, o exemplo mais paradigmático é o do sindicato dos ferroviários que cria, no final da década de vinte, o Instituto dos Ferroviários com o objectivo de albergar os filhos órfãos dos sócios do Sindicato dos Ferroviários do Sul, a quem procuravam fornecer instrução, formação moral e preparação técnica, educando-os em regime de internato (quando obtinham bom aproveitamento continuavam os estudos em Lisboa tirando um curso industrial ou superior, sendo-lhes assegurada subsistência, matrículas, livros, entre outras coisas, pelo Instituto).

Na perspectiva de Victor de Sá, a República foi um período rico de experiência proletária, ensinamentos tácticos e aprofundamentos ideológicos, em que se deu um aumento considerável da imprensa operária e a irrupção de um forte movimento sindical e reivindicativo no sector rural; por outro lado, foi o período de desilusão da classe trabalhadora, depois da expectativa favorável que o período da Propaganda incrementara ${ }^{41} \mathrm{~A}$ agudização das lutas sociais ficou a dever-se a vários factores, entre os quais a não execução de qualquer programa social que havia sido prometido - tanto que nem mesmo a promessa do sufrágio universal foi satisfeita -, o agravamento da repressão contra os trabalhadores, a participação na

\footnotetext{
${ }^{40}$ FREIRE, João. Anarquistas e Operários. Ideologia, ofício e práticas soiais: o anarquismo e o operariado e Portugal, 1900-1940. Porto: Edições Afrontamento, 1992. P.157.

${ }^{41}$ SÁ, Victor de. Roteiro da Imprensa Operária e Sindical 1836-1986. Lisboa: Editorial Caminho, 1991. p. 103.
} 
Grande Guerra e a carestia da vida. ${ }^{42}$

Pode-se considerar que o desenvolvimento das formações de cariz educativo para adultos constitui no seu conjunto uma extensão da forma escolar, na medida em que existe um contracto didáctico, uma prática social distinta, uma representação e planificação do acto de aprendizagem, um tempo didáctico, disciplina, formas de excelência e trabalho. Segundo Rogério Fernandes:

A centúria de Oitocentos testemunha entre nós, como noutros países da Europa, a emergência do movimento da educação popular, caracterizado pela multiplicidade das iniciativas e pela diversidade, quando não pelo antagonismo político-ideológico dos respectivos promotores e agentes: cursos nocturnos e escolas móveis, animados por associações de diferentes matizes ideológicos, pelo estudantado, ou pelas autoridades políticas, círculos católicos operários, organizados pela Igreja Católica ou por militantes laicos na perspectiva da difusão da doutrina social cristã. ${ }^{43}$

Escolas e cursos nocturnos foram criados para prolongar o tempo do ensino e de estudo depois do pôr-do-sol. Apareceram na segunda metade do século XIX e manter-se-iam no século XX. A primeira referência a cursos nocturnos no Barreiro encontrámo-la em Fevereiro de 1864, quando o professor de ensino primário, Luís de Almeida Reis, requereu à Câmara um subsídio para iluminação da "Aula Noturna que ele espontaneamente tem estabelecido n'esta Villa para aquelles que não podem frequentar de dia e atendendo a grande utilidade publica que dali resulta a instrução", tendo a Câmara aprovado uma ajuda de mil réis mensais, enquanto o professor conservasse a referida aula. ${ }^{44}$

Mas não era só na escola oficial que funcionava um curso nocturno. Também, a Sociedade dos Penicheiros mantinha, com

${ }^{42}$ Ibidem. p. 103.

${ }^{43}$ FERNANDES, Rogério. Uma Experiência de Formação de Adultos na 1. ${ }^{a}$ República. A Universidade Livre Para Educação Popular 1911-1917, Lisboa: Câmara Municipal de Lisboa, 1993. p. 9.

${ }^{44}$ Livro de actas das sessões da Câmara Municipal do Barreiro. 1861-1865, $21 \mathrm{Fev} 1864$. 
muito êxito, em 1893, na sua sede, aulas de instrução primária diurnas para as crianças e nocturnas para os adultos, que estavam a cargo da Associação das Escolas Móveis e utilizavam o método João de Deus. Igualmente, de acordo com o noticiado na imprensa local, no final de 1900, a Associação de Classe dos Operários Corticeiros inaugurou as aulas nocturnas de primeiras letras, destinadas aos filhos dos associados e aos próprios associados que as quisessem frequentar. ${ }^{45}$ Mas, já em plena República, na Sociedade de Instrução e Recreio Barreirense, "Os Penicheiros", em 28 de Janeiro de 1920, foi rejeitada uma proposta de se estabelecer um curso diurno e nocturno na sala da colectividade devido "a mandarem grandes despesas, que a mesma colectividade não pode acarretar". ${ }^{46}$

A ideia de alargar o conjunto de intervenções relativas ao movimento de educação popular a esferas mais amplas do ensino e da cultura conduziu à criação das universidades populares. Segundo Rogério Fernandes, as universidades populares consagraram a sua acção à vulgarização cultural e ao que apelidaríamos de ensino secundário. ${ }^{47}$

\footnotetext{
${ }^{45}$ A Voz do Barreiro, Periodico semanal, absolutamente independente, litterario e noticioso, ano I, n. 5, Barreiro, 23 Dez 1900. p. 3.

${ }^{46}$ Os Penicheiros, Actas da Direcção de 20 de Outubro de 1917 a 24 de Maio de 1922, 28 de Janeiro de 1920. p. 11.

${ }^{47}$ FERNANDES, Rogério. ob. cit., 1993. p. 9. As Universidades Populares Livres, caracterizadas por Victor de Sá como "uma autêntica obra de extensão universitária", foram criadas ao longo da 1. ${ }^{a}$ República, por iniciativa de intelectuais progressistas (SÁ, J. Victor de, Universidades Populares na 1. ${ }^{a}$ República. In: Universidade(s). História. Memória. Perspectivas. Actas 1 - Congresso História da Universidade $7 .^{\circ}$ Centenário, 5 a 9 de Março de 1990, Coimbra, 1991, p. 471). Em 1919 surge, em Lisboa, a Universidade Popular Portuguesa, com sede na rua Luís de Derouet e com secções no Barreiro e em Setúbal, que oferecia cursos públicos, conferências, sala de leitura e propunha-se promover excursões, sessões cinematográficas, concertos musicais, etc. Os cursos ministrados abrangiam a área das ciências exactas, da arquitectura, da música; as conferências incidiam sobre figuras demarcadas do novo humanismo da época, como Tolstoi, Gandhi, João de Deus, Guerra Junqueiro, entre tantos outros. Ao conselho administrativo estavam ligados vários anarquistas e sindicalistas, pelo que não seria de admirar que a acção da Universidade se exercesse também em Sindicatos (Comércio, Arsenal, Metalurgia, Construção Civil, Chapelaria) e fora de Lisboa (Barreiro, Setúbal), através das secções que aí possuía. A Universidade Popular Portuguesa foi inaugurada
} 
A III Secção da Universidade Popular Portuguesa, com sede no Barreiro, foi inaugurada solenemente em 20 de Fevereiro de 1921, um domingo, pelas 14 horas, contando com a presença de mais de mil pessoas na assistência, tendo sido conferencista o Dr. Reis Santos com o tema "O estado actual da sociedade portuguesa - A educação - O papel das Universidades Populares no ressurgimento nacional" ${ }^{48}$ No artigo de jornal, onde se publicava a notícia da abertura dessa Secção, fazia-se também um apelo à população barreirense para se associar àquela organização, inscrevendo-se como sócios, e era dada a indicação dos locais onde seriam distribuídos os boletins de inscrição, aos interessados. Segundo o mesmo artigo, encontrava-se já agendada a realização de uma "segunda festa", para breve, com uma conferência, a que se seguiria uma sessão de animatógrafo; também se dava conta da proximidade da inauguração de uma exposição dos trezentos volumes dos "melhores escritores nacionais e estrangeiros" que fariam parte da biblioteca móvel. Estava também nos projectos da III Secção, a criação de um orfeão, bem como outros trabalhos não discriminados.

No que concerne à influência da Universidade Livre no Barreiro, uma das explicações, por nós alvitrada, para a escassa informação que encontrámos sobre essa instituição, poderá estar relacionada com o facto de os cursos práticos da Universidade Livre servirem, fundamentalmente, os trabalhadores dos serviços, as mulheres e os jovens, enquanto que a

em Abril de 1919 e, pelo decreto n. ${ }^{\circ} 5781$ de 10 de Maio do mesmo ano, assinado pelo então Ministro da Instrução Pública Dr. Leonardo Coimbra, considerada como instituição de utilidade nacional. Foram criadas delegações em várias cidades e vilas do país. O seu grande objectivo era levar a educação a todas as pessoas. Politicamente, estava mais à esquerda do que a Universidade Livre para a Educação Popular, que fora fundada em 1911 por iniciativa de Alexandre Ferreira (pai do poeta José Gomes Ferreira), um benemérito extremamente activo e membro da maçonaria. Na Universidade Popular Portuguesa trabalhavam homens de esquerda ou comunistas, como Bento de Jesus Caraça. De salientar que houve várias instituições do mesmo tipo com a designação de "Livres" ou "Populares", pelo que, por vezes, se confundem.

${ }^{48}$ Acção. Ano I, Número 9, Barreiro, 5 de Março de 1921. A delegacia da Universidade Popular de Lisboa, no Barreiro, era constituída por Augusto Penedo, Tomé Vieira e António José da Silva (os dois primeiros nomes são, respectivamente, o do director e

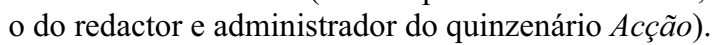


classe operária constituía uma clientela muito mais diminuta, pelo que não teria muita razão de existir uma dependência dessa universidade no Barreiro, sendo essa uma terra de operariado. No entanto, cabe aqui salientar que a Universidade Livre acolhia, nos seus cursos práticos, principalmente os portadores de habilitações mais baixas e que, apesar da representação da classe operária entre esses trabalhadores ser inferior à dos sectores dos serviços, "o certo é que os inscritos nos cursos práticos eram certamente aqueles que tinham menos possibilidades de acesso à escola durante a infância e a juventude" ${ }^{49}$ A outra explicação que lançamos prende-se também com a constatação feita por Rogério Fernandes de que a Universidade Popular Portuguesa tinha ligações bastante mais estreitas com o movimento sindical do que a Universidade Livre, o que vem aclarar o motivo de termos encontrado mais referências àquela instituição do que a esta. ${ }^{50}$

Em contraponto com a grave falta de escolas primárias de que sofria o Barreiro, a iniciativa particular reconhecia a utilidade da cultura nas massas populares: "Todas as colectividades recreativas e desportivas possuem uma bem fornecida biblioteca onde os seus associados, nas horas de ócio, podem recrear o espírito e cultivar a inteligência". ${ }^{51}$ Exemplo disso é o que acontecia na colectividade, "Os Penicheiros", onde havia uma biblioteca para os sócios que podiam fazer a requisição de livros para leitura domiciliária ${ }^{52}$.

Para muitos, o tempo passado na escola era tido como um tempo preparatório para o trabalho. Os pais olhavam a instrução elementar na escola, não como um meio de disciplinar, mas, como um meio de se adquirir a leitura, a escrita, a aritmética, a costura e o "ponto de meia"; em suma, o capital essencial para uma profissão - o pagamento para subsistir. A decisão de mandar uma criança para a escola ou trabalhar dependia, todavia, de outros factores, tais como, o tamanho da família e a posição

\footnotetext{
${ }^{49}$ FENANDES, Rogério. ob. cit., 1993. p. 86.

${ }^{50}$ Ibidem. p. 89.

${ }^{51}$ O Concelho do Barreiro, 25 Dez 1931, Número único. p. 5.

52 Os Penicheiros. Actas da Direcção de 23 de Julho de 1924 a 29 de Dezembro de 1926, 24 Fev 1926.
} 
que a criança ocupava no seio desta; contudo, tal decisão constituía uma despesa adicional para a família: "for the working classes as a whole the introduction of compulsory education imposed a considerable extra burden on the family budget until $1891 " .{ }^{53}$ Normalmente, a probabilidade de o filho mais novo ter a chance de frequentar a escola era maior do que a dos seus irmãos mais velhos; estes teriam de ir trabalhar, a fim de contribuírem com algum suplemento monetário para o orçamento familiar, ou, no caso das raparigas, de ficarem em casa.

De acordo com os dados publicados no n. ${ }^{\circ} 49$ do Boletim do Trabalho Industrial de 1910, o Barreiro tinha duas associações: a "Associação de Classe dos Operários Corticeiros do Barreiro", com 176 sócios, e a "Associação Commercial e Industrial do Barreiro", com 93 associados. ${ }^{54}$ Conforme as informações fornecidas pela Associação dos Corticeiros do Barreiro, "os aprendizes começam quase sempre de dez a catorze anos, ganhando por dia 100 a 140 réis e subsídios proporcionalmente ao que produzem"; ; relativamente à questão se havia nos estabelecimentos fabris aprendizes com menos idade do que a legalmente permitida, a resposta foi: "Há de todas as idades e são os abusos frequentes", ${ }^{66}$ no que respeita a duração do trabalho: "Nos horários não há distinções para homens, nem para mulheres e menores, regulando de 9 a 11 horas, segundo as estações do ano"; $; 7$ numa das respostas chamavam a atenção para o facto de "A admissão de mulheres e menores e o emprego das máquinas têm provocado sensivelmente a baixa no preço da mão de obra". ${ }^{58}$ As respostas às questões que se prendiam com a instrução ("Os aprendizes frequentam

\footnotetext{
${ }^{53}$ HURT, J. S. Elementary Schooling and the Working Classes 1860-1918. London: Routledge \& Kegan Paul, Toronto and Buffalo: University of Toronto Press, 1979. p. 158-159.

${ }^{54}$ Aliás, apenas duas associações do Barreiro, das muitas que existiam, responderam ao inquérito mandado fazer pelo Governo (através de uma portaria de 26 Nov 1909) junto das associações de classe, sobre a situação do operariado e da indústria nacional. ${ }_{55}$ Ministério do Fomento, Direcção Geral do Commercio e Industria, Repartição do Trabalho Industrial, Boletim do Trabalho Industrial. n. 49. Lisboa: Imprensa Nacional, 1910. p. 408.

${ }^{56}$ Ibidem. p. 409.

${ }^{57}$ Ibidem. p. 408.

${ }^{58}$ Ibidem. p. 411.
} 
regularmente a escola primária?" e "No caso negativo, quais são as razões d'esse facto?") são elucidativas da realidade de uma parte da população infantil: "Não frequentam escola alguma" e "É o prolongado labor das oficinas não lhes permitir frequentarem". 59

A questão do trabalho infantil não é, contudo, um fenómeno novo. Aliás, como havia constatado Philippe Ariès, o trabalho das crianças manteve o mesmo carácter da sociedade medieval: "la précocité du passage chez les adultes". ${ }^{60}$ No entanto, a Revolução Industrial trouxe modificações nas condições de emprego da mão-de-obra infantil. Já nos inícios do século XX, em 1915, o projecto de lei apresentado na Câmara dos Deputados, em 26 de Agosto, obrigava os patrões ou donos de fábricas, oficinas ou outros estabelecimentos das cidades de Lisboa e Porto a não terem ao seu serviço indivíduos analfabetos com menos de 30 anos de idade, e determinava que, os patrões que tivessem ao seu serviço indivíduos menores de 16 anos, ficavam obrigados a permitirem-lhes a frequência às escolas mais próximas, durante as horas de trabalho; o não cumprimento estaria sujeito a multa e a fiscalização seria exercida pela Inspecção das Escolas Móveis. ${ }^{61}$

Em entrevista dada a um jornal local, em Fevereiro de 1921, Joaquim Vicente França, professor e director da escola Conde de Ferreira masculina da vila, indagado sobre a necessidade de dotar o Barreiro com uma escola primária superior ou com uma escola industrial, disse ser de opinião que a escola superior daria melhores resultados, e frisava que os habitantes do Barreiro não tinham, na sua maioria, os meios suficientes para educarem os filhos em Lisboa ou em Setúbal. Salientava, ainda, o facto do Barreiro ser uma das terras do país que apresentava maior percentagem de alunos a exame de instrução primária; como vantagem da instalação da escola primária superior, apontava o seguinte argumento:

Note, que o meio essencialmente operário que é esta vila, exige a escola industrial, mas esta não ensina a criança saída do ensino

\footnotetext{
${ }^{59}$ Ibidem. p. 413.

${ }^{60}$ ARIÈS, Philippe. L'Enfant et la Vie Familiale sous l'Ancien Régime. Paris: Éditions du Seuil, 1973. p. 216.

${ }^{61}$ Diário do Governo, II Série, N. ${ }^{\circ} 200.30$ Ago 1915, artigos $1 .^{\circ}$ e 2. ${ }^{\circ}$.
} 
primário geral, ao passo que aquela pode beneficiar as duas partes necessitadas [...] a escola industrial, beneficia o operário, enquanto a escola primária superior beneficia estes pelos ensinos correlativos que se podem anexar e as crianças que se queiram educar, pois o seu curso equivale ao quinto ano do liceu. ${ }^{62}$

Numa outra entrevista, dada pelo mesmo professor, em 1923, sobre a necessidade de construção de um novo edifício escolar ou a ampliação do existente, publicada no artigo intitulado "Instrucção primária. A educação da criança barreirense", dizia: "As fábricas já nos roubam muitas creanças que em vez de se instruírem e se educarem, para poderem depois ser uns verdadeiros operários, se atrofiam, se envenenam e se anarquisam". ${ }^{63}$

Como havia um predomínio de economias domésticas frágeis, a atitude face ao quotidiano tinha como principal referência o garantir da sobrevivência das famílias. Dessa forma, a criança era encarada como um "valor económico" a rentabilizar nas oficinas ou nas fábricas, maximizando-se a sua força de trabalho, pelo que o investimento escolar passava, então, para segundo plano. Para uma parte significativa da população trabalhadora, prescindir do rendimento auferido pelas crianças, impedindo-as de trabalhar para frequentarem a escola, constituía um investimento a longo prazo a que poucos queriam ou podiam atrever-se. Os hipotéticos rendimentos mais elevados, em termos de benefícios materiais, conseguidos pela mobilidade social que a escola poderia proporcionar, dentro de princípios meritocráticos, não eram tidos como compensatórios na óptica dessas famílias, para quem eram mais importantes as questões da sobrevivência do "hoje" em vez das incertezas do "amanhã". No seu livro Le Mouvement Ouvrier, Bénigno Cacérès, quando se debruçou sobre o trabalho infantil, constatou que:

\footnotetext{
${ }^{62}$ Acção, ano I, n. 8, Barreiro, 15 Fev 1921. Volvidos vários anos, mais concretamente em Dezembro de 1945, foi criada a Escola Industrial e Comercial Alfredo da Silva, que viria a ser inaugurada em Janeiro de 1947, tendo sido o primeiro estabelecimento de ensino secundário do concelho do Barreiro.

${ }^{63}$ Acção, ano III, n. 51, Barreiro, 5 Jun 1923.
} 
L'admission des enfants dans les fabriques dès l'âge de huit ans est pour les parents un moyen de surveillance, pour les enfants um commencement d'apprentissage, pour la famille une ressource. L'habitude de l'ordre, de la discipline et du travail doit s'acquérir de bonne heure et la plupart des mains - d'oeuvre industrielles exigent une dextérité, une prestesse qui ne s'obtiennent que par une pratique assez longue et qui ne peut être commencée trop tôt. L'enfant entré à huit ans dans l'atelier, façonné au travail, ayant acquis l'habitude de l'obéissance et possédant les premiers éléments de l'instruction primaire, arrivera à dix ans plus capable de supporter la fatigue, plus habile et plus instruit qu'un enfant du même âge élevé jusque-là dans l'oisivité en prenant pour la première fois le tablier du travail. ${ }^{64}$

\section{Notas finais}

Em termos históricos, a escola moderna surge associada à produção de uma nova ordem económica, social e política. A escola tem um papel importante na produção de uma força de trabalho disciplinada, organizada em moldes de se integrar na crescente racionalidade da organização do trabalho, baseado na hierarquia, na partição das tarefas e na separação entre trabalhador e produto do seu trabalho. Dessa forma se cria uma consonância entre a escola e o mundo exterior, pelo que em função dos destinos laborais e sociais dos estudantes se diversificaram os conteúdos programáticos. $\mathrm{O}$ sistema educacional viu-se comprometido com as dominâncias ideológicas da sociedade. $\mathrm{O}$ ensino que se pretendia que chegasse a todos trazia na sua raiz marcas que determinavam a superioridade de determinados grupos sociais sobre outros, resultado da própria industrialização e, por outro, do controlo estatal sobre o cidadão baseado em princípios sociais de hierarquização estratificada da sociedade. Assim, "A instrução converteuse em meio de conferir a cada estrato social uma função e um estatuto". ${ }^{65}$

${ }^{64}$ CACÉRÈS, Bénigno. Le Mouvement Ouvrier. Paris: Éditions du Seuil, 1984. p. 18. ${ }^{65}$ MAGUALHÃES, Justino. "Imaginário e realidade educativa: escolarização da gesta e da narrativa pátrias", In: Alberto Filipe Araújo; MAGUALHÃES Justino (org.), História, Educação e Imaginário. Centro de Estudos em Educação e Psicologia, Instituto de Educação e Psicologia, Universidade do Minho, 2000. p. 36. 
A instituição escolar é tida como um produto típico da modernidade, pois tem a sua origem na produção histórica do Estado moderno, emergindo na História como necessidade da formação do ser social construtor de uma nova sociedade burguesa. A necessidade funcional de promover a cultura letrada poderá estar relacionada com uma crescente necessidade de mão-de-obra instruída, quer a nível social quer cognitivo, que fosse capaz de obedecer a padrões de pontualidade, respeito, polidez, disciplina e produtividade, qualificações que correspondiam ao trabalhador moderno. Contudo, parece que não se articulam estas qualidades com os interesses dos industriais para quem a mão-de-obra mais barata das crianças e das mulheres lhes era mais útil, uma vez que os operários especializados auferiam salários mais elevados.

Há um certo carácter mítico em torno da educação popular, pois as memórias tendem a conservar o lado mítico dos acontecimentos. Educação popular e educação permanente são coisas distintas que não podem ser confundidas. Podemos fazer remontar a génese da educação popular à Revolução Francesa. Mas será que se pode falar em educação popular sem se fazer referência à classe operária, à sua história e aos seus movimentos? A questão é delicada, atendendo a que o movimento comunista impôs o princípio que não há legitimidade popular fora da classe trabalhadora, ainda por cima que é difícil fazer da educação popular o produto de um movimento popular. Em suma, todos (operários e patrões, católicos e laicos, conservadores e socialistas) colocaram a sua pedra na construção do grande edifício da educação popular que transcende todas as oposições e antagonismos.

Segundo Peter Burke, se o paradigma tradicional da escrita da história está em crise, também o novo paradigma da escrita da história não está isento de problemas de definição, de fontes, de método e de explicação. Uma das questões que levanta é a seguinte:

Por exemplo, se a cultura popular é a cultura "do povo", quem é o povo? São todos: o pobre, as "classes subalternas", como costumava chamá-las o intelectual marxista Antonio Gramsci? São os analfabetos ou os incultos? Não podemos presumir que as divisões 
económicas, políticas e culturais em uma determinada sociedade necessariamente coincidam. ${ }^{66}$

O próprio significado de educação lhe levanta igualmente dúvidas: "E o que é educação? Apenas o treinamento transmitido em algumas instituições oficiais como escolas ou universidades? As pessoas comuns são ignorantes ou simplesmente têm uma educação diferente, uma cultura diferente das elites? ${ }^{67}$.

Aliados à construção dos Estados-Nação apareceram os modernos sistemas educativos, nos quais a escolarização é tida como primordial e única via de se entender a educação. Quando o homem se vê impregnado deste princípio, à semelhança do que diz Mircea Eliade para o homem religioso que "não pode viver senão numa atmosfera impregnada do sagrado ${ }^{68}$, também o homem alfabetizado não pode viver sem a palavra escrita, pois é ela que lhe dá a chave do conhecimento. Para os que advogam a escola como único meio possível de se ascender ao conhecimento, o professor assume um papel idêntico ao do padre na igreja: enquanto este último é o intermediário entre Deus e o homem, o professor é o intermediário entre o homem e o conhecimento. Outra semelhança se encontra em termos espaciais: a igreja é o recinto sagrado e privilegiado para a comunicação com Deus, enquanto que a escola é o local especializado e também sagrado onde flui o conhecimento teórico do homem e das coisas.

A escola não é mais do que uma invenção histórica contemporânea da revolução liberal e industrial, tendo como marca o início da modernidade. Dá-se uma separação entre o aprender e o fazer em termos espaciais, passando a escola a ser o local onde se aprende. Desse modo, a forma escolar não é mais do que uma nova maneira de encarar a aprendizagem, criando uma cisão com a visão tradicionalista em que a experiência imersa na sociedade era a chave-mestra. A forma escolar corresponde à

\footnotetext{
${ }^{66}$ BURKER, Peter (org.). A Escrita da História: Novas Perspectivas. São Paulo: Editora da UNESP, 1992 (1991). p. 23.

${ }^{67}$ Ibidem.

${ }^{68}$ ELIADE, Mirce. O Sagrado e o Profano. A essência das religiões. Lisboa: Edição Livros do Brasil, 1975. p. 42.
} 
dimensão da pedagogia. Ao ter-se constituído progressivamente como a forma tendencialmente única de conceber a educação conferiu à escola o protagonismo monopolizante da acção educativa, valorizando, apenas, os saberes adquiridos pela via escolar, subalternizando e mesmo aniquilando outros saberes.

\section{Referências}

ARIÈS, Philippe. L'Enfant et la Vie Familiale sous l'Ancien Régime. Paris: Éditions du Seuil, 1973.

BARROS, João de. O Problema Educativo Português. Ensaio crítico. Lisboa: Imprensa Libanio da Silva, 1920.

BUISSON, Ferdinand. Dictionnaire de Pédagogie et d'Instruction Primaire (extraits). Paris: Éditions Kimé, 2000 (1880-1887).

BURKE, Peter (org.). A Escrita da História: Novas Perspectivas. São Paulo: Editora da UNESP, 1992 (1991).

CACÉRÈS, Bénigno. Le Mouvement Ouvrier. Paris: Éditions du Seuil, 1984.

CAMPORESI, Piero. O Pão Selvagem. Lisboa: Editorial Estampa, 1990.

CANDEIAS, António (dir. e coord.). Alfabetização e Escola em Portugal nos Séculos XIX e XX. Os Censos e as Estatísticas. Lisboa: Fundação Calouste Gulbenkian, 2004.

CHARTIER, Anne-Marie. Le lecture scolaire entre histoire des disciplines et histoire culturelle. In: Éducation et Sociétés. Revue Internationale de Sociologie de L'Éducation, n. 4, Issy-les-Moulineaux/France: De Boeck Université, 1999/2. p. 115-129.

DURKHEIM, Émile. De la Division du Travai Social. 2.è édition. Paris: Presses Universitaires de France, 1986 (1893).

ELIADE, Mircea. O Sagrado e o Profano. A essência das religiões. Lisboa: Edição Livros do Brasil, 1975.

FERNANDES, Rogério. O Pensamento Pedagógico em Portugal, 2. a ed. 
Lisboa: Instituto da Cultura e Língua Portuguesa, Ministério da Educação, 1992.

FERNANDES, Rogério. Uma Experiência de Formação de Adultos na 1. ${ }^{a}$ República. A Universidade Livre Para Educação Popular 1911-1917. Lisboa: Câmara Municipal de Lisboa, 1993.

FREIRE, João. Anarquistas e Operários. Ideologia, oficio e práticas sociais: o anarquismo e o operariado em Portugal, 1900-1940. Porto: Edições Afrontamento, 1992.

GEREMEK, Bronislaw. A Piedade e a Forca. História da miséria e da caridade na Europa. Lisboa: Terramar, 1995 (1986).

HOBSBAWN, E. J. A Era do Capital 1848-1875. Lisboa: Editorial Presença, 1979.

HOGGART, Richard. As Utilizações da Cultura 2. Aspectos da vida cultural da classe trabalhadora. Lisboa: Editorial Presença, 1975 (1957).

HURT, J. S. Elementary Schooling and the Working Classes 1860-1918. London: Routledge \& Kegan Paul, Toronto and Buffalo: University of Toronto Press, 1979.

ILLICH, Ivan D. Une Société Sans École. Paris: Éditions du Seuil, 1971.

KUCZYNSKI, Jürgen. Les Origines de la Classe Ouvriére. Paris: Hachette, 1967.

MAGALHÃES, Justino. Imaginário e realidade educativa: escolarização da gesta e da narrativa pátrias. In: ARAÚJO, Alberto Filipe; MAGALHÃES, Justino (org.). História, Educação e Imaginário. Centro de Estudos em Educação e Psicologia, Instituto de Educação e Psicologia. Universidade do Minho, 2000. p. 35-45.

MÓNICA, Maria Filomena. A sociedade, o Estado e a educação popular: Inglaterra, Portugal e Japão. In: Análise Social, vol. XII (48), 1976-4. p. 853- 871.

NÓVOA, António. Os professores: quem são? donde vêm? para onde vão?. In: STOER, Stephen (org.). Educação, Ciências Sociais e Realidade Portuguesa. Uma Abordagem Pluridisciplinar. Porto: Edições Afrontamento, 1991. p. 59-130. 
RAMOS, Rui. O chamado problema do analfabetismo: as políticas de escolarização e a persistência do analfabetismo em Portugal (séculos XIX e XX). In: Ler História, 35, 1998. p. 45-70.

RODRIGUES, Manuel Ferreira; MENDES, José Amado. História da Indústria Portuguesa. Da Idade Média aos Nossos Dias. Mem-Martins: Associação Industrial Portuguesa, Publicações Europa-América, 1999.

SÁ, J. Victor de. Universidades Populares na 1. ${ }^{\text {a }}$ República. In: Universidade(s). História. Memória. Perspectivas. Actas 1 - Congresso História da Universidade 7. ${ }^{\circ}$ Centenário, 5 a 9 de Março de 1990, Coimbra, 1991.

SÁ, Victor de. Roteiro da Imprensa Operária e Sindical 1836-1986. Lisboa: Editorial Caminho, 1991.

VINCENT, Guy. L'École Primaire Française. Etude Sociologique. Lyon: Presses Universitaires de Lyon, Editions de la Maison des Sciences de l'Homme, 1980.

WEBER, Max. A Ética Protestante e o Espirito do Capitalismo. Lisboa: Editorial Presença, 1983 (escrito entre 1904 e 1905). 